\title{
The application of natural zeolite to cement concrete intended for communications surfaces
}

\author{
Małgorzata Linek ${ }^{1, *}$, Wojciech Żebrowski ${ }^{2}$, and Pawet Wolka ${ }^{3}$ \\ 1,2,3 Kielce University of Technology, Faculty of Civil Engineering and Architecture, Department of \\ Transportation Engineering, Tysiąclecia Państwa Polskiego Street 7,25-314 Kielce, Poland
}

\begin{abstract}
The article presents the application of a cement substitute in the form of natural zeolite to cement concrete. The reference mix design intended for communications surfaces and a mix of modified composition taking into consideration zeolite content were prepared. The basic parameters of concrete mix components were specified, including basalt aggregate, cement and zeolite. The influence of the applied zeolite of a grain-size distribution up to $50 \mu \mathrm{m}$ on the obtained parameters of concrete mix and hardened concrete was determined. It was observed that the applied zeolite contributes to the modification of the internal structure of concrete composite and consequently to the increase of the mechanical and physical parameters of hardened concrete tested within diversified standard periods of time. Due to the fact that the resistance of concrete to cyclic freezing and thawing is the determinant of concrete durability, in the case of pavement structure, hardened concretes were subject to a frost resistance assessment. The influence of zeolite content on both internal and external frost resistance of hardened concrete was specified. SEM observations of the internal structure of concretes exposed to the influence of freezingthawing cycles proved the advantageous changes of zeolite occurrence in concrete mix. A reduction of cement quantity and its replacement thereof with the suggested zeolite allows obtaining a pavement quality concrete of a more favourable internal micro structure and distinguished by higher parameters.
\end{abstract}

\section{Purpose and the scope of research}

The article is aimed at the assessment of the suitability of natural zeolite in the composition of cement concrete intended for communications surfaces. The basic properties of basalt aggregate, cement and zeolite were determined. It was assessed whether the applied zeolite influences a change in the parameters of the internal structure of hardened cement concrete, the change of physical and mechanical properties of concrete intended for communications surfaces. The source of natural zeolite formation in nature was the settlement of volcanic ash and then its reaction with lake slats [1].

The included the assessment of basalt aggregate, cement and zeolite parameters. The series labeled B was a basalt aggregate fraction of $2 / 8 \mathrm{~mm}$ and $8 / 16 \mathrm{~mm}$. In the case of the

\footnotetext{
* Corresponding author: linekm@tu.kielce.pl
} 
aggregate the following were determined: volume density $\left(\rho_{\mathrm{a}}\right)$ according to [2], absorbability (W) according to [3], abrasion resistance $\left(\mathrm{M}_{\mathrm{DE}}\right)$ according to [4] and crushing resistance (LA) according to [5]. The series labeled $\mathrm{C}$ was low-alkali Portland cement (less than $0.6 \% \mathrm{Na}_{2} \mathrm{O}$ content) and the series $\mathrm{Z}_{50}$ was natural zeolite of a grain-size distribution of $50 \mu \mathrm{m}$. The natural zeolite was dosed, as the substitute of part of cement. The material from the area of eastern Slovakia - Nižný Hrabovec area was analysed.

The influence of the applied natural zeolite on the change of concrete mix parameters was determined. The experiment assumed performing two series of concrete mix. The first series was the so-called reference type of concrete mix the composition of which was in compliance with standard requirements [6]. This concrete mix was indicated as MB, and the results obrtained in the case of this mixture were considered as reference values. The second series included a mixture of a modified composition, in which part of cement (15\%) was replaced with natural zeolite. This mixture was indicated as $\mathrm{MZ}_{50}$. The tests included: mix density using a cylinder of $8 \mathrm{dm}^{3}$ capacity according to [7], consistency using concrete slump method according to [8] and air contents using manometer method according to [9]

The prepared concrete mix series $\mathrm{MB}$ and $\mathrm{MZ}_{50}$ after being arranged into (cubic moulds

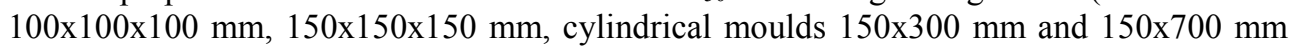
according to [10]) were subject to standard curing [11] for the assumed research periods ( 7 , 28,56 and 90 days).

The experiment assumed to perform two series of concrete. The first series was reference concrete $(\mathrm{CB})$, in accordance with the requirements of [6]. The next series included concrete with cement substitute in the form of natural zeolite (series $\mathrm{CZ}_{50}$ ). Concretes for communications surfaces were analyzed.

The determined concrete parameters included the following: volume density $\left(\rho_{0}\right)$ according to [12], absorbability $(\mathrm{N})$ according to [6], compressive strength $\left(\mathrm{f}_{\mathrm{cm}}\right)$ according to [13], splitting tensile strength $\left(\mathrm{f}_{\mathrm{ct}}\right)$ according to [14], concrete bending strength $\left(\mathrm{f}_{\mathrm{cf}}\right)$ according to $[15,16]$, stripping strength according to [17], abrasion resistance according to [18], maximum depth of water penetration according to [19] and after diversified curing periods.

The frost resistance of concretes series $\mathrm{CB}$ and $\mathrm{CZ}_{50}$ was determined for the assumed number of 200 freezing and thawing cycles in water. The evaluation of frost resistance refers to the determination of two parameters. The first parameter is the change of compressive strength of samples subject to freezing and defrosting cycles $(\Delta \mathrm{R})$. The second parameter is the change of sample weight after the frost resistance test $(\Delta G)$ determined according to [6]. The resistance to scaling for the internal frost resistance of $\mathrm{CB}$ and $\mathrm{CZ}_{50}$ series concretes has been determined for the assumed number of 56 freezing and thawing cycles in potassium formate. The evaluation of frost resistance refers to the determination of sample weight after frost resistance test $(\Delta \mathrm{S})$ determined according to [6].

In order to assess the impact of the used natural zeolite on the changes of the internal structure, concretes of series $\mathrm{CB}$ and $\mathrm{CZ}_{50}$ were subject to observations in a scanning electron microscope (SEM). The preparation of samples and the interpretation of the obtained results were in compliance with those described in literature works $(20,21)$. Fresh fractures were prepared using concretes $\mathrm{CB}$ and $\mathrm{CZ}_{50}$. The preparation surface was observed by means of a scanning electron microscope SEM and each time it was more than $1.0 \mathrm{~cm}^{2}$. The magnification ranged from $200 \mathrm{x}$ to $100000 \mathrm{x}$.

\section{Materials}

According to the obtained results it was proved that the grain-sized distribution of the analyzed basalt aggregate ranged from $2 \mathrm{~mm}$ to $8 \mathrm{~mm}$ and from $8 \mathrm{~mm}$ to $16 \mathrm{~mm}$ - Fig. 1a. 

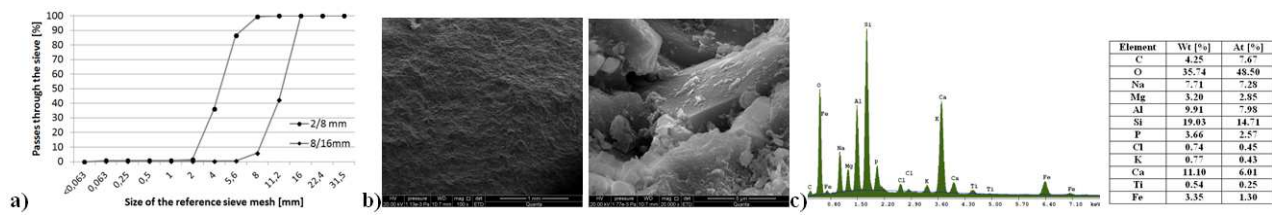

Fig. 1. Characterization of the tested basalt aggregate, a) grain-size distribution, b) SEM image of basalt grain, c) image of chemical microanalysis.

Based on the observations conducted by means of a Quanta Feg 250 Scanning Electron Microscope it was proved that the fraction of basalt grit contains quarto crystals of a conchoidal fracture. The grains are of an irregular, angular and sharp shape - Fig. $1 \mathrm{~b}$.

Based on the chemical microanalysis of the analysed porphyry grit, the occurrence of the following elements, i.e. oxygen, silicon, calcium, aluminum and sodium was proved (Fig. 1c). An aggregate grading composition of mix series MB was selected according to the guidelines of [6] taking into consideration limit curves of good grain size distribution (Fig. 2).

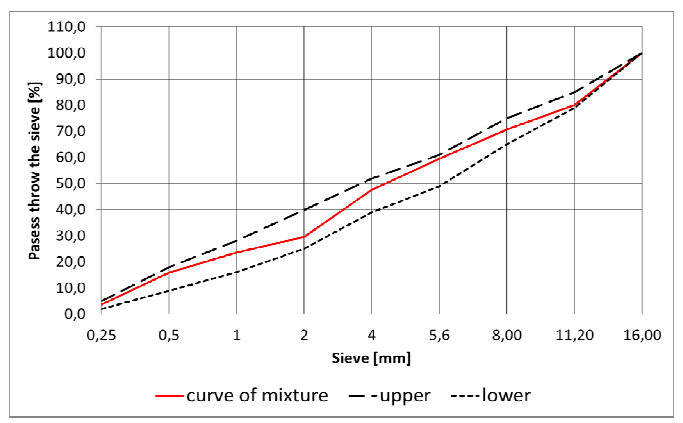

Fig. 2. Designed aggregate mixture curve, together with limit curves (lower and upper)

Quantity selection of the remaining components (Table 1) was based on experimental methods maintaining the consistency of reference mix at S1 level and taking into consideration the exposure class XF4, with the air amount between 4,5-5,5\%.

Table 1. Compositions of the designed mixes of the following series MB and MZ 50 .

\begin{tabular}{|c|c|c|c|}
\hline \multirow{2}{*}{ components } & density & $\mathrm{MB}$ & $\mathrm{MZ}_{50}$ \\
\cline { 2 - 4 } & $\mathbf{k g} / \mathbf{d m}^{\mathbf{3}}$ & $\mathbf{k g} / \mathbf{m}^{\mathbf{3}}$ & $\mathbf{k g} / \mathbf{m}^{\mathbf{3}}$ \\
\hline CEM I 42.5N MSR/NA & 3.10 & 370 & 314.5 \\
\hline Natural zeolite & 2.30 & - & 55.5 \\
\hline Fine aggregate 0/2mm & 2.66 & 598 & 598 \\
\hline Basalt 2/8mm & 3.16 & 864 & 864 \\
\hline Basalt 8/16mm & 3.16 & 753 & 753 \\
\hline Water & 1.00 & 148 & 148 \\
\hline Plasticizer & 1.14 & 2.6 & 2.6 \\
\hline Aerating agent & 1.00 & 1.7 & 1.7 \\
\hline
\end{tabular}




\section{Results}

\subsection{Assessment of the influence of natural zeolite on the parameters of concrete mixes}

According to the obtained laboratory test results (Table 2) it was proved that the air content in mixes with zeolite is non-compliant with the standard requirements [6]. In the case of $\mathrm{MZ}_{50}$ mix, the air content was the lowest at 3.5\%. Significant diversification was proved in the case of volume density. The mix of $M Z_{50}$ series was distinguished by the highest parameter, while the mix of the MB series was distinguished by the lowest parameter. The difference was $3 \%$. Based on the obtained results, no significant influence of the natural zeolite on the concrete mix consistency was proved. In the case of all analyzed mixes, the consistency defined in experimental test corresponded to S1 class.

Table 2. Parameters of mixtures of the following series MB and $\mathrm{MZ}_{50}$.

\begin{tabular}{|c|c|c|c|}
\hline \multirow{2}{*}{$\operatorname{mix}$} & Density & Consistency & Air contents \\
\cline { 2 - 4 } & $\mathbf{k g} / \mathbf{m}^{\mathbf{3}}$ & $\mathbf{m m}$ & $\mathbf{\%}$ \\
\hline $\mathrm{MB}$ & 2493 & $20-\mathrm{S} 1$ & 5.5 \\
\hline $\mathrm{MZ}_{50}$ & 2569 & $0-\mathrm{S} 1$ & 3.5 \\
\hline
\end{tabular}

\subsection{Assessment of the influence of natural zeolite on the selected physical and mechanical parameters of hardened concrete}

During scientific research, the amount of the required samples was determined using students' T-distribution assuming the significance level of 0.05 . The minimum essential number of samples ranged between 4 and 5, depending on the type of the conducted test. In case of such assumptions, 6 samples were selected, which, each time, were intended for the laboratory tests.

According to the obtained experimental test results (Fig. 3a) it was proved that the natural zeolite significantly influences volume density of hardened concrete. Concretes of the $\mathrm{CZ}_{50}$ series were distinguished by a higher volume density, while concretes of the $\mathrm{CB}$ series of a lower volume density. The examined feature is also strictly dependent on the length of curing period. The diversification of the examined feature in the case of the $\mathrm{CZ}_{50}$ and $\mathrm{CB}$ concrete type was approx. $72,74,85$ and $79 \mathrm{~kg} / \mathrm{m}^{3}$ after $7,28,56$ and 90 days accordingly.

According to the obtained experimental test results (Fig. 3b) it was proved that the natural zeolite did not significantly change the absorbability of hardened concrete. It was proved that absorbability of the concrete series $\mathrm{CB}$ and $\mathrm{CZ}_{50}$ does not exceed $3.2 \%$. It should be emphasised that all of the analyzed concrete types complied with the requirements of [6] standard with regard to absorbability. 

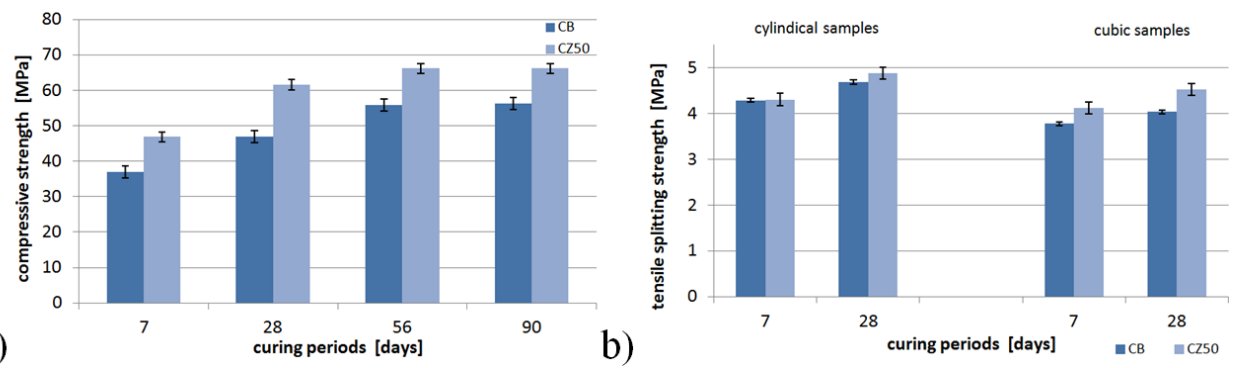

Fig. 3. Average hardened concrete density (a) and absorbability (b) of series $\mathrm{CB}$ and $\mathrm{CZ}_{50}$ during diversified curing periods.

The favourable influence of zeolite on the reduction of water penetration depth by 12 $\mathrm{mm}$ was proved, which was not referred to in the increase of hardened concrete resistance to the influence of freezing and thawing cycles. In the case of concrete of the $\mathrm{CZ}_{50}$ series, the comparable decrease of resistance $(\Delta \mathrm{R})$ and sample mass $(\Delta \mathrm{G})$ was proved after 200 cycles of frost resistance test, in regard to concrete of CB series - Table 3.

Table 3. Parameters of concrete series $\mathrm{CB}$ and $\mathrm{CZ}_{50}$.

\begin{tabular}{|c|c|c|c|c|c|c|c|}
\hline \multirow[t]{2}{*}{ concrete } & \multicolumn{2}{|c|}{$\begin{array}{c}\text { Maximum depth of } \\
\text { water penetration, } \\
{[\mathrm{mm}]}\end{array}$} & \multicolumn{2}{|c|}{$\begin{array}{c}\text { Concrete frost } \\
\text { resistance test, } \\
{[\%]} \\
\end{array}$} & \multirow{2}{*}{$\begin{array}{c}\begin{array}{c}\text { Mass of } \\
\text { exfoliated } \\
\text { material, [g] }\end{array} \\
\Delta \mathbf{S}\end{array}$} & \multicolumn{2}{|c|}{$\begin{array}{c}\text { Abrasion } \\
\text { resistance, } \\
{\left[\mathrm{cm}^{3} / 50 \mathrm{~cm}^{2}\right]}\end{array}$} \\
\hline & $\bar{X}$ & $\sigma$ & $\Delta \mathbf{R}$ & $\Delta \mathbf{G}$ & & $\bar{X}$ & $\sigma$ \\
\hline $\mathrm{CB}$ & 56 & 6 & 2.15 & 0.05 & 0.00 & 10.2 & 0.3 \\
\hline $\mathrm{CZ}_{50}$ & 40 & 8 & 3.20 & 0.02 & 0.00 & 10.9 & 0.4 \\
\hline
\end{tabular}

According to the analysis of the obtained test results it was proved that concrete of the $\mathrm{CZ}_{50}$ series is distinguished by favourable mechanical parameters. Compared to the $\mathrm{CB}$ concrete series, concrete of the $\mathrm{CZ}_{50}$ series, has higher resistance parameters and is distinguished by comparable absorbability. The results obtained after the frost resistance test (Table 3) are also the confirmation thereof.

\subsection{Assessment of the influence of natural zeolite on the microstructure of hardened concrete}

According to the conducted SEM observations it was proved that the natural zeolite contributes to the change of internal structure of cement matrix (Fig. 4, 5).

a)
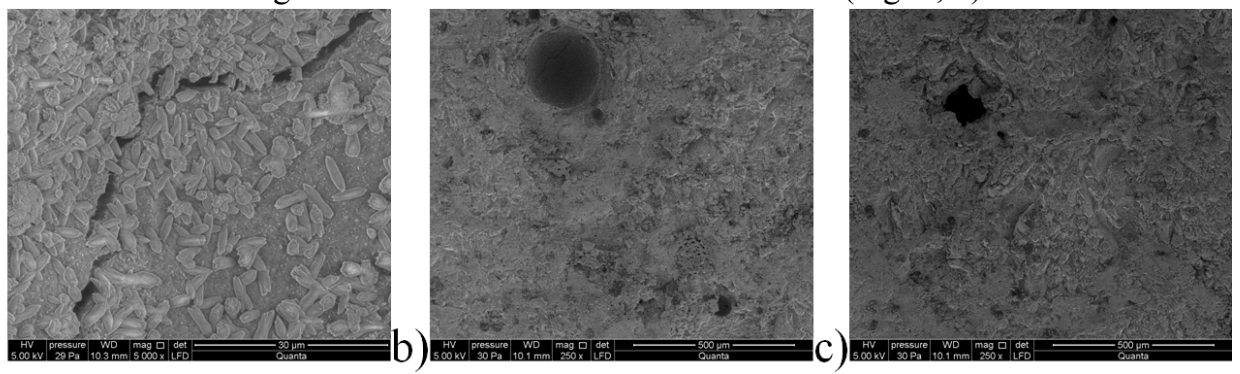

Fig. 4. Internal structure of cement concrete series CB: a) air pores, b) cement matrix, c) contact areas between cement matrix and aggregate grains. 
The internal walls of air voids undergo cracking of a width up to $2-3 \mu \mathrm{m}$. Crystallization in granular-fibrous form occurs (Fig. 4a). The internal structure of concrete of the CB series is distinguished by non-continuous contact areas between the aggregate grains and the cement matrix (Fig. 4c). The cement matrix, in the case of concrete of the CB series, is consistent. The diameters of the air voids are up to $240 \mu \mathrm{m}$ (Fig. $4 \mathrm{~b}$ ).
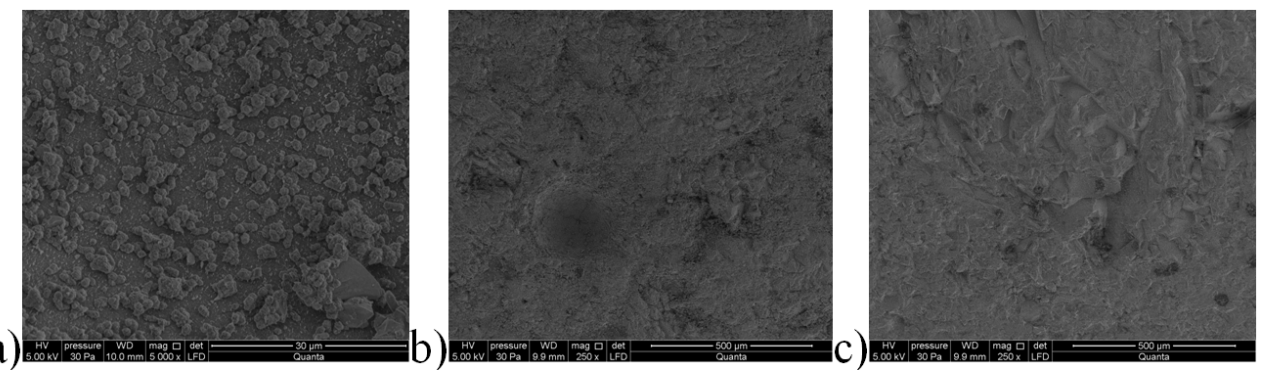

Fig. 5. Internal structure of cement concrete series $\mathrm{CZ}_{50}$ : a) air pores, b) cement matrix, c) contact areas between cement matrix and aggregate grains.

The cement matrix, in the case of concrete of the $\mathrm{CZ}_{50}$ series, is consistent and the crystallization of hydrated calcium silicate occurs in grained form (Fig. 5b). The crystallization of ettringite, with the length of single crystals of which is up to $43 \mu \mathrm{m}$, occurs in the cement matrix. The internal structure of concrete of the $\mathrm{CZ}_{50}$ series is distinguished by continuous contact areas between the aggregate grains and the cement matrix (Fig. $5 \mathrm{c}$ ). The internal walls of air voids undergo cracking of a width up to $2-4 \mu \mathrm{m}$ and crystallization in granular form occurs (Fig. 5a).

\section{Conclusions}

According to the conducted laboratory tests, the following conclusions have been reached: - natural zeolite composition contains oxygen, sulfur, aluminum, potassium, carbon, sodium, calcium, magnesium;

- application of zeolite to the mix influences the increase of mechanical parameters (compressive strength and splitting tensile strength) and performance parameters of concrete (abrasion resistance and stripping resistance) and as a consequence the opportunity to extend the operation time and structure durability.

- natural zeolite used in concrete mix contribute to the increase of concrete ultimate compressive strength after standard curing period by $16 \%$ and stabilization of growth after an extended period of up to 90 days at a level of $15 \%$;

- natural zeolite used in concrete mix contribute to the increase of concrete's ultimate stripping strength after a standard curing period by $47 \%$, which is very important in the case of airport pavements because the pull-off test is based on the concept that the tensile stress is related to the mortar's tensile adhesion strength;

- natural zeolite used in concrete mixes does not significantly affect the change of concrete bending strength and concrete resistance to the influence of freezing and thawing cycles;

- applied natural zeolite favourably affect the changes of the internal structure of concrete composite (contact areas between aggregate grains and cement matrix, crystallization of cement matrix and air void);

It is possible to clearly reduce the amount of cement used and $\mathrm{CZ}_{50}$ concrete is distinguished by more favourable parameters with respect to performance characteristics. The higher abrasion resistance of $\mathrm{CZ}_{50}$ concrete, together with its higher stripping strength 
prove the increased resistance of this concrete to the destructive influence of vehicular traffic.

\section{References}

1. G. Bundyra-Oracz, D. Siemaszko-Lotkowska, "Zeolite - puzzolan additive to concrete", Building industry, Production Engineering, Architecture, vol. 4, pp. 72-74, 2010.

2. PN-EN 1097-7: 2008 Investigations of mechanical and physical properties of aggregates - Part 7: Determination of filler density - Pycnometric method.

3. PN-EN 1097-6:2013-11 Investigations of mechanical and physical properties of aggregates - Part 6: Determination of particle density and water absorption.

4. PN-EN 197-1:2012 Cement part 1: Composition, specyfications and conformity criteria for common cements.

5. PN-EN 1097-2:2010 Investigations of mechanical and physical properties of aggregates - Part 2: Methods for determining resistance to grinding.

6. NO 17-A204:2015 Airfield concrete pavements - Requirements and test methods for cement concrete pavements.

7. PN-EN 12350-6:2011 Testing fresh concrete. Part 6: Density.

8. PN-EN 12350-2:2011 Testing fresh concrete. Part 2: Testing the consistency with the cone fall method.

9. PN-EN 12350-7:2011 Testing fresh concrete. Part 7: Air content - Pressure methods.

10. PN-EN 12390-1:2013 Testing hardened concrete - Part 1: Shape, dimensions and other requirements for specimens and moulds.

11. PN-EN 12390-2:2011 Testing hardened concrete - Part 2: Making and curing speciments for strength tests.

12. PN-EN 12390-7:2011 Testing hardened concrete - Part 7: Desity of hardened concrete.

13. PN-EN 12390-3:2011 Testing hardened concrete - Part 3: Compressive strenth of test specimens.

14. PN-EN 12390-6:2011 Testing hardened concrete - Part 6: Tensile splitting strength of test specimens.

15. M. Linek, P. Nita "Pavement quality cement concrete of extended operational durability”, XXIX International Baltic Road Conference, Tallinn, 2017.

16. PN-EN 12390-5:2011 Testing hardened concrete - Part 5: Flexural strength of test specimens.

17. PN-EN 1542:2000 Products and systems for protection and repair of concrete structures - Test methods - Peel adhesion measurement

18. PN-EN 13892-3:2005 Methods for testing materials for undercoats - Part 3: Determination of abrasion resistance according to Bohme

19. PN-EN 12390-8:2011

20. M. A. Glinicki, "Durability of concrete in road surfaces. Effect of microstructure, materials design, diagnostics" (in Polish), IBDiM, Warsaw, 2011.

21. M. Linek, "Surface concrete with improved parameters of physical and mechanical on the loads caused by forced temperature" (in Polish), PhD Thesis, Kielce, 2013. 